Yüzüncü Y1 Üniversitesi
Tarim Bilimleri Dergisi

Araştırma Makalesi (Research Article)

\title{
Karar Ağacı Algoritmaları ile Organik Ürün Tüketici Tercihlerinin Belirlenmesi: Iğdır İli Örneği
}

\section{İbrahim Hakkı KADİRHANOĞULLARI ${ }^{*}$, Köksal KARADAŞ ${ }^{2}$, Ömer ÖZGER ${ }^{3}$, Meryem KONU KADIRHANOĞULLARI ${ }^{4}$}

\author{
${ }^{1,3,4}$ Iğdır Üniversitesi, Uygulamalı Bilimler Yüksekokulu, Organik Tarım İşletmeciliği Bölümü, Iğdır, Türkiye \\ ${ }^{2}$ Iğdır Üniversitesi, Ziraat Fakültesi, Tarım Ekonomisi Bölümü, Iğdır, Türkiye \\ ${ }^{1}$ https://orcid.org/0000-0002-9640-8910 2https://orcid.org/0000-0003-1176-3313 3https://orcid.org/0000-0001-8494-687X \\ ${ }^{4}$ https://orcid.org/0000-0001-7359-7061 \\ *Sorumlu yazar e-posta: i.kadirhanogullari@gmail.com
}

\section{Makale Bilgileri}

Geliş: 24.09.2020

Kabul: 31.12.2020

Online Yayınlanma 30.03.2021

DOI: 10.29133/yyutbd.799465

\section{Anahtar kelimeler}

Karar ağaçları,

Organik ürün tüketimi,

Organik tarım.
Öz: Organik tarım ve gıda ürünleri insan sağlığı başta olmak üzere gıda güvenliği, hayvan refahı ve doğayı koruduğu için tercih edilmekte ve bu konu hakkında yapılan çalışmalar gün geçtikçe artmaktadır. Bu çalışmanın amacı, Iğdır İli kentsel alanda yaşayan tüketicilerin organik tarım ve gıda ürünleri tutum ve satın alma davranışlarını ortaya koymaktır. Çalışma kapsamında, 168 tüketici ile yüz yüze anket yöntemi kullanılarak veriler toplanmış ve istatiksel analizi veri madenciliği yöntemlerinden karar ağacı algoritması kullanılarak belirlenmiştir. Organik gıda ürünleri satın almayı etkileyen en belirleyici değişkenin Hanedeki Birey Sayısı olduğu görülmüştür. Hanedeki Birey Sayısı 6 ve daha altında olan $(\mathrm{n}=125, \% 86.2)$ kişiden Hanedeki Birey Sayısı 7 ve daha üstünde olanlara $(n=14, \% 8.3)$ oranla daha fazla organik ürün tükettiği gözlenmiştir. Diğer önemli belirleyici faktörler ise "Aylık Hane Halkı Geliri” ve "Eğitim Durumu” olmuştur.

\section{Determination of Organic Product Consumer Preferences with Decision Tree Algorithms: Sample of Igdir Province}

\section{Article Info}

Received: 24.09.2020

Accepted: 31.12 .2020

Online Published 30.03.2021

DOI: 10.29133/yyutbd.799465

\section{Keywords}

Decision Trees,

Organic product

consumption,

Organic agriculture.

\begin{abstract}
Organic agriculture and food products are preferred because they protect human health food safety animal welfare and nature and studies on this subject are increasing day by day. The aim of this study is to reveal the organic agriculture and food products attitudes and purchasing behaviors of the consumers living in the urban area of Igdir. Within the scope of the study, data were collected with 168 consumers using face to face questionnaire method and statistical analysis was determined using decision tree algorithm, one of the data mining methods. It has been observed that the most determinant variable affecting the purchasing of organic food products is the number of individuals in the household. It was observed that people with 6 or less Households $(n=125$, 86.2\%) consumed more organic products than those with 7 or more households ( $\mathrm{n}=14,8.3 \%$ ) other important determinants were "Monthly Household Income" and "Education Status".
\end{abstract}




\section{Giriş}

Organik Tarım kelimesi Türkiye'de "Ekolojik veya Organik", Almanya ve Kuzey Avrupa dillerinde "Ekolojik", Fransa, İtalya, İspanya'da "Biyolojik" (Kurt, 2006) ve İngiltere'de "Organik" (Kurga ve Erdal, 2014) olarak kullanılmaktadır.

1970'li yıllarda insanlar gübrelerin ve sentetik kimyasalların zararlı etkilerini kendilerinde ve çevrelerinde görmeye başladığı sırada (Hakan, 2017), insan sağlığı ilk sırada olmak üzere tüm canlıların ve çevrenin korunmasında etkili olan organik tarım sistemi (Eryılmaz ve ark, 2015), ilgi görmeye başlamıştır

Organik tarım, çevreye ve bilhassa insan sağlığına zarar vermeyen ve üretilirken kimyasal girdi kullanılmayan, üretimden tüketime kadar her aşaması kontrollü ve sertifikalı bir tarımsal üretim şekli olarak ifade edilmektedir (Anonim, 2020a).

Organik tarım dünyadaki tarım alanlarının \%1'inde yapılmaktadır. Organik tarım alanlarının \%3'ü Afrika, \%7'si Kuzey Amerika, \%8'i Asya, \%15'i Latin Amerika, \%27'si Avrupa ve \%40'1 Okyanusya' da yer alırken, organik üreticilerin bölgesel dağılımı ise \%1 Kuzey Amerika ve Okyanusya, \%15 Avrupa, \%17 Latin Amerika, \%26 Afrika ve \%40 Asya olarak sıralanmaktadır. Kişi başına en fazla organik ürün tüketen ülkeler İsviçre, Lüksemburg ve Danimarka olarak bilinmektedir (FIBL, 2016).

Türkiye'de organik tarım 1980'li yıllarda Avrupalı ithalatçıların talepleri doğrultusunda kuru üzüm ve kuru incir üretimiyle başlamış ( Rehber ve Turan, 2002) ve sonra ülkeye yayılmıştır.

Organik tarım sıfır girdi kullanımı, tüm dünyayı besleme, tüm tarımsal üretimin organik olması gibi bir amacı olmamasına rağmen (Kurga ve Erdal, 2014) birçok ülkede sektör olarak gelişimi devam etmektedir.

Tüketicilerin organik tarım ve ürünlerini geleneksel ürünlere kıyasla tercihleri ve satın alma kararları farklılık göstermektedir. Organik tarım ve ürünlerini satın alma süreci, organik ürünleri tanıma ve diğer ürünlerle farkının anlaşılmasıyla başlamaktadır. Organik tarım ve gıda ürünlerinin konvansiyonel alternatiflerine oranla tercih edilmesinin nedenleri arasında İnsan sağlığına zarar vermemesi, organik gıdanın güvenli olması, hayvan refahının sağlanması, çevrenin korunması ve sertifikalı olması gibi faktörler gösterilmektedir (Eryılmaz ve ark, 2015; İnci ve ark., 2017; Çam ve Karakaya, 2018).

Bu çalışmada, Iğdır ili kentsel alanda yaşayan tüketicilerin organik tarım ve gıda ürünleri tutum ve satın alma davranışlarını ortaya koymak amacıyla karar ağacı algoritması kullanılmıştır.

\section{Materyal ve Yöntem}

$\mathrm{Bu}$ çalışmanın materyalini, Iğdır ili merkez ilçe kentsel alanda bulunan ve örnekleme yöntemiyle seçilen bireylerin organik gıda ürünleri tüketimi konusundaki bilgi düzeylerinin ve tercihlerinin belirlenmesi için yüz yüze görüşme yöntemiyle yapılan anketlerden elde edilen veriler oluşturmuştur.

\subsection{Verilerin toplanma aşaması}

Iğdır ili merkez nüfusu 140267 olup (Anonim, 2020b) bu ana kitleyi en iyi temsil etmesi için aşağıda formülü verilen 'Basit Tesadüfi Örnekleme Yı̆̆ın Oran Tahmini' metodu (Yamane, 2010) kullanılarak elde edilen anket verileri değerlendirilmeye tabii tutulmuştur

$$
n=\frac{N \cdot t^{2} \cdot p q}{(N-1) D^{2}+t^{2} p q}
$$

$\mathrm{n}=$ Örneğe alınacak birey sayısı

$\mathrm{N}=$ Küme büyüklüğü (140 267)

$\mathrm{D}=$ Kabul edilen veya arzu edilen örnekleme hatası $(0.1)$

$\mathrm{t}=$ Standart normal dağılım değeri (2.576)

$\mathrm{q}=1-\mathrm{p}(0.5)$

$\mathrm{p}=$ Hesaplanmas 1 istenen oran $(0.5)$ 
$\mathrm{n}=\left(\frac{140267 \times 2.576^{2} \times 0.5 \times 0.5}{(140267-1) \times 0.1^{2}+2.576^{2} \times 0.5 \times 0.5}\right)=165($ Yamane, 2010).

Iğdır ili kentsel alanında tüketicilerin organik gıda tutumlarıyla ilgili veri bulunmadığından $p$ ve q değerleri 0.5 olarak alınmış, $\mathrm{p}=$ organik gıda tüketenler, $\mathrm{q}=$ organik gıda tüketmeyenler olarak kabul edilmiştir. Seçilen örneklem büyüklüğünün yeterli olduğu belirlenmiş ve anket 168 kişiye uygulanmıştır.

\subsection{Verilerin analiz aşaması}

$\mathrm{Bu}$ çalışmada veri madenciliği süreci yöntem olarak izlenmiş ve modelleme aşamasında karar ağacı algoritması kullanılmıştır.

Kolay yorumlanması ve anlaşılabilir olmasından dolayı karar ağaçları, karar vericiler için avantaj sağlayan algoritma olup sınıflandırma ve tahmin için çoklukla kullanılan bir veri madenciliği yaklaşımıdır (Chien ve Chen, 2008; Çalış ve ark., 2014; Karadas ve Kadirhanogullari, 2017; Karakaya ve ark.,2018).

Karar ağacı analizinden sonra elde edilen sınıflandırma sonuçlarından test geçerliliği, duyarlık ve özgünlük değerleri hesaplanmıştır (Çizelge 2).

İlk olarak organik gıda ürünleri satın alma bağımlı değişkeni ile yaş, cinsiyet, eğitim durumu, medeni durum, meslek durumu, aylık hane halkı geliri bağımsız değişkenleri için SPSS'te CHAID, CRT, QUEST ve Exhaustive CHAID algoritmaları uygulanmış ve en yüksek doğruluk oranını veren CHAID algoritması ile karar ağacı oluşturulup sonuçlar yorumlanmıştır.

\section{Bulgular}

Organik gıda ürünleri satın almada anketler değerlendirilirken öncelikle demografik özellikler ele alınmıştır. Çizelge 1'de görüldüğü üzere Iğdır ilinde Organik gıda ürünleri satın alma anketine katılan 168 bireyin çoğunluğunu erkekler oluşturmaktadır ( $\mathrm{n}=103, \%$ 61.3). Medeni durum sınıfında bekâr ve evli olanların frekanslarının birbirine yaklaşık olarak yakın olduğu görülmektedir (Evli $n=84$, \%50.0; Bekâr $n=82, \% 48.8$; Boşanmış $n=2, \% 1.2$ ). Hanedeki birey sayısı üç kişiden oluşan tüketicilerin oranı $(\mathrm{n}=37, \% 22.0)$ dört kişiden oluşan tüketicilerin oranı $(\mathrm{n}=29, \% 17.3)$ beş kişiden oluşan tüketicilerin oranı $(\mathrm{n}=24, \% 14.3)$ altı kişiden oluşan tüketicilerin oranı $(\mathrm{n}=22, \% 13.1)$ iki kişiden oluşan tüketicilerin oranı $(n=19, \% 11.63)$ ve diğerlerinin toplamı $(n=37, \% 22.1)$ olarak bulunmuştur. Eğitim düzeyini en çok lisans mezunu ( $\mathrm{n}=86, \% 51.2)$ ile ön lisans $(\mathrm{n}=34, \% 20.2)$ mezunları oluşturmaktadır. Meslek gruplarına bakıldığında memur olan ( $\mathrm{n}=61$ kişi \%36.3), öğrenci olan ( $\mathrm{n}=46, \% 27.4)$, ev hanımı olan ( $\mathrm{n}=25 \% 14.9)$ kişiden oluştuğu ve çoğunluğun memur olduğu görülmektedir. Aylık hane halk1 gelirinde çoğunluğu 2001-3000 grubunda yer alan ( $\mathrm{n}=44, \% 26.2)$ ile 3001-4000 olan ( $\mathrm{n}=29, \% 17.3)$ oluşturmaktadır.

Şekil 1'de organik gıda ürünleri satın alma bağımlı değişkeni için CHAID Algoritması ile meydana gelen karar ağacına baktığımızda, ağacın ilk olarak, hanedeki birey sayısı sorusundan dallandığı görülmektedir. Organik Gıda Ürünleri Satın Alma bağımlı değişkeni için ağacın dallanmasındaki en etkili faktörün "Hanedeki Birey Sayısı" olduğu görülmektedir. Anketi cevaplayan 168 kişiden 139 kişi (\%82.7) organik gıda ürünleri kullandığını ve 29 kişi (\%17.3) kullanmadığını belirtmiştir. Hanedeki birey sayısı $\leq 6$ kişi olan 125 kişi (\%86.2) organik gıda ürünleri kullandığını, 20 kişi ise (\%13.8) organik gıda ürünleri kullanmadığını belirtmiştir. Hanedeki birey sayısı yedi olan 2 kişi (\%28.6) organik gıda ürünleri kullandığını, 5 kişi ise (\%71.4) organik gıda ürünleri kullanmadığını belirtmiştir. Hanedeki birey sayısı $\geq 7$ kişi olan 12 kişi (\%75.2) organik gıda ürünleri kullandığını, 4 kişi ise (25.0) organik gıda ürünleri kullanmadığını belirtmiştir

Hanedeki birey sayısı bağımsız değişkeninin aylık hane halkı geliri bağımsız değişkeninden dallandığı görülmektedir. Hanedeki birey sayısı altı ve daha altında olan 145 kişiden aylık hane halkı geliri 2001-3000 ve daha altında olan 65 kişi (\%86.7) organik gıda ürünleri kullandığını, 10 kişi ise (\%13.3) organik gıda ürünleri kullanmadığını belirtmiştir. Aylık hane halkı geliri 3001-4000£ olan 15 kişi (\%62.5) organik gıda ürünleri kullandığını, 9 kişi ise (\%37.5) organik gıda ürünleri kullanmadığını belirtmiştir. Aylık hane halkı geliri 3001-4000€ ve daha üstünde olan 45 kişi (\%97.8) organik gıda ürünleri kullandığını, 1 kişi ise (\%2.2) organik gıda ürünleri kullanmadığını belirtmiştir.

Aylık hane halkı geliri bağımsız değişkeninin eğitim durumu bağımsız değişkeninden dallandığı görülmektedir. Aylık hane halkı geliri 3001-4000 arasında olan 24 kişiden eğitim durumu ilkokul ve 
daha altında olanların hepsi ( $\mathrm{n}=5$ kişi, $\% 100)$ organik gıda ürünleri kullandığını belirtmiştir. Eğitim Durumu ön lisans olan 6 kişi (\%100) organik gıda ürünleri kullanmadığını belirtmiştir. Eğitim Durumu ön lisanstan daha yukarı olan 10 kişi (\% 76.9) organik gıda ürünleri kullandığını, 3 kişi ise (\%23.1) organik gıda ürünleri kullanmadığını belirtmiştir.

Çizelge 1. Organik gıda ürünleri satın alma demografik özellikler

\begin{tabular}{|c|c|c|c|c|c|}
\hline & & \multicolumn{3}{|c|}{ Organik gıda satın alır mısınız? } & \multirow[b]{3}{*}{ Yüzde(\%) } \\
\hline & & Evet & & Hayır & \\
\hline & & Say1(N) & Yüzde(\%) & $\operatorname{Say} 1(N)$ & \\
\hline \multirow[t]{2}{*}{ Cinsiyet } & Erkek & 84 & 81.55 & 19 & 18.45 \\
\hline & Kadın & 55 & 84.62 & 10 & 15.38 \\
\hline \multirow[t]{3}{*}{ Medeni Durum } & Evli & 76 & 90.48 & 8 & 9.52 \\
\hline & Bekâr & 61 & 74.39 & 21 & 25.61 \\
\hline & Boşanmış & 2 & 100 & 0 & 0.00 \\
\hline \multirow[t]{11}{*}{ Hanedeki Birey Sayısı } & $1 \mathrm{Kişi}$ & 11 & 78.57 & 3 & 21.43 \\
\hline & 2 Kiși & 18 & 94.74 & 1 & 5.26 \\
\hline & 3 Kişi & 29 & 78.38 & 8 & 21.62 \\
\hline & 4 Kişi & 27 & 93.10 & 2 & 6.90 \\
\hline & 5 Kişi & 20 & 83.33 & 4 & 16.67 \\
\hline & 6 Kişi & 20 & 90.91 & 2 & 9.09 \\
\hline & 7 Kiși & 2 & 28.57 & 5 & 71.43 \\
\hline & 8 Kişi & 8 & 80.00 & 2 & 20.00 \\
\hline & 9 Kiși & 3 & 100 & 0 & 0.00 \\
\hline & 10 Kişi & 1 & 100 & 0 & 0.00 \\
\hline & $11 \mathrm{Kişi}$ & 0 & 0.00 & 2 & 100 \\
\hline \multirow[t]{7}{*}{ Eğitim Durumu } & Okuryazar Değil & 4 & 100 & 0 & 0.00 \\
\hline & İlkokul & 5 & 62.50 & 3 & 37.50 \\
\hline & Ortaokul & 9 & 90,00 & 1 & 10.00 \\
\hline & Lise & 15 & 78.95 & 4 & 21.05 \\
\hline & Ön Lisans & 27 & 79.41 & 7 & 20.59 \\
\hline & Lisans & 72 & 83.72 & 14 & 16.28 \\
\hline & Lisansüstü & 7 & 100 & 0 & 0.00 \\
\hline \multirow[t]{7}{*}{ İş Durumu } & Çalışmıyor & 8 & 66.67 & 4 & 33.33 \\
\hline & Öğrenci & 34 & 73.91 & 12 & 26.09 \\
\hline & Memur & 57 & 93.44 & 4 & 6.56 \\
\hline & Özel sektör & 5 & 55.56 & 4 & 44.44 \\
\hline & Ev hanımı & 21 & 84.00 & 4 & 16.00 \\
\hline & Serbest meslek & 4 & 100 & 0 & 0.00 \\
\hline & İşçi & 10 & 90.91 & 1 & 9.09 \\
\hline \multirow[t]{8}{*}{ Aylık Hane Halkı Geliri } & 1000£ ve Alt1 & 17 & 77.27 & 5 & 22.73 \\
\hline & 1001€-2000€ & 19 & 79.17 & 5 & 20.83 \\
\hline & 2001€-3000£ & 38 & 86.36 & 6 & 13.64 \\
\hline & 3001€-4000£ & 19 & 65.52 & 10 & 34.48 \\
\hline & 4001£-5000£ & 20 & 95.24 & 1 & 4.76 \\
\hline & 5001€-6000€ & 9 & 100 & 0 & 0.00 \\
\hline & 6001€-7000€ & 5 & 71.43 & 2 & 28.57 \\
\hline & 7001€ ve Üzeri & 12 & 100 & 0 & 0.00 \\
\hline
\end{tabular}




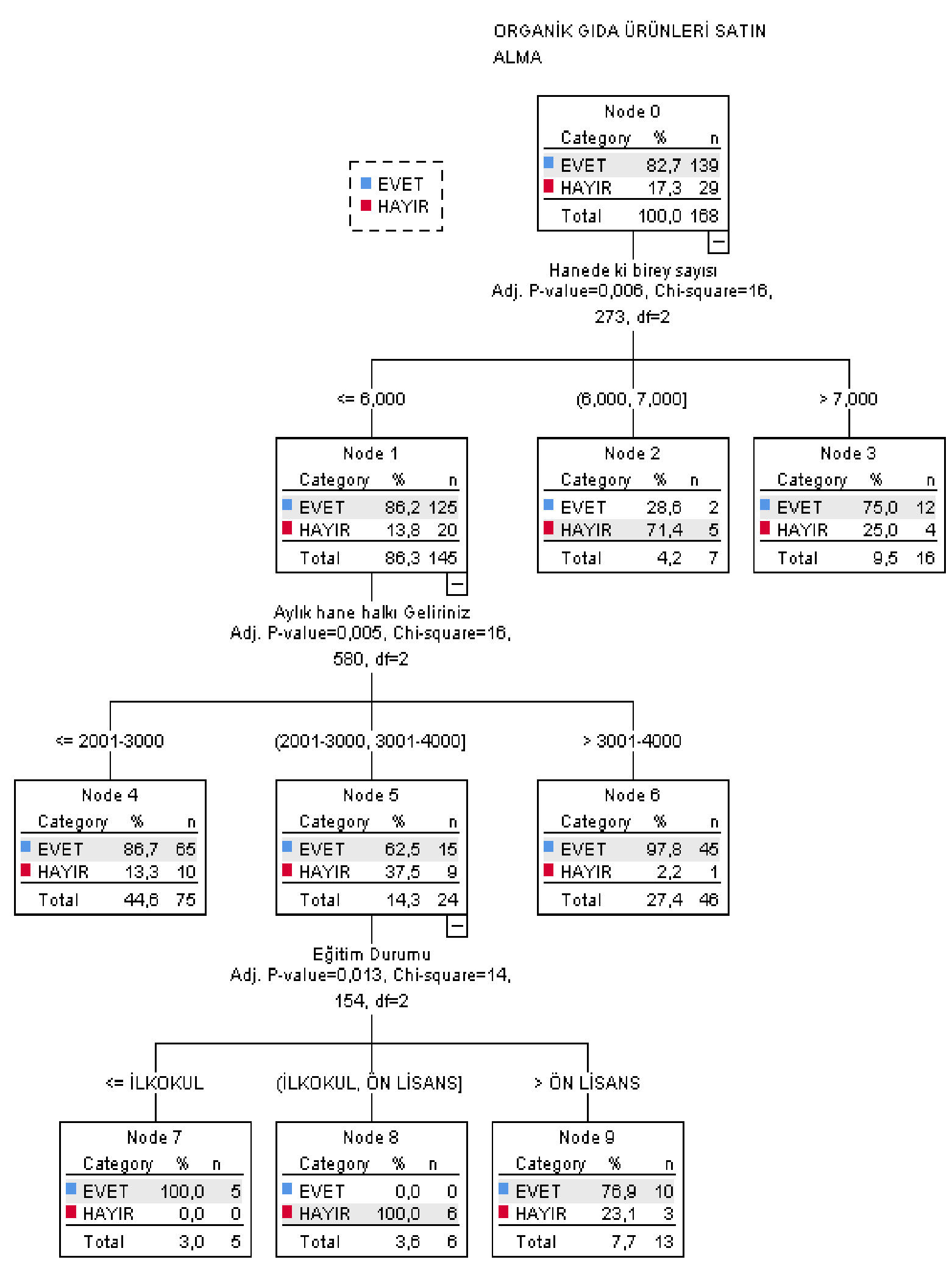

Şekil 1: Organik gıda ürünleri satın alma karar ağacı. 
Çizelge 2. Karar ağacı analizi sınıflandırma sonuçları

\begin{tabular}{lll}
\hline Sinıflandıma & \multicolumn{2}{c}{ Tahmin Edilen } \\
Gözlemlenen & Evet & Hayır \\
\hline Evet & 137 & 2 \\
Hayır & 18 & 11 \\
Genel Yüzde & $\% 92.3$ & $\% 7.7$ \\
\hline
\end{tabular}

Yukarıdaki sonuçlara göre;

Duyarlil1k \%88.4

Özgüllük \%84.6

Test geçerliliği \% 88.1 olarak tespit edilmiştir.

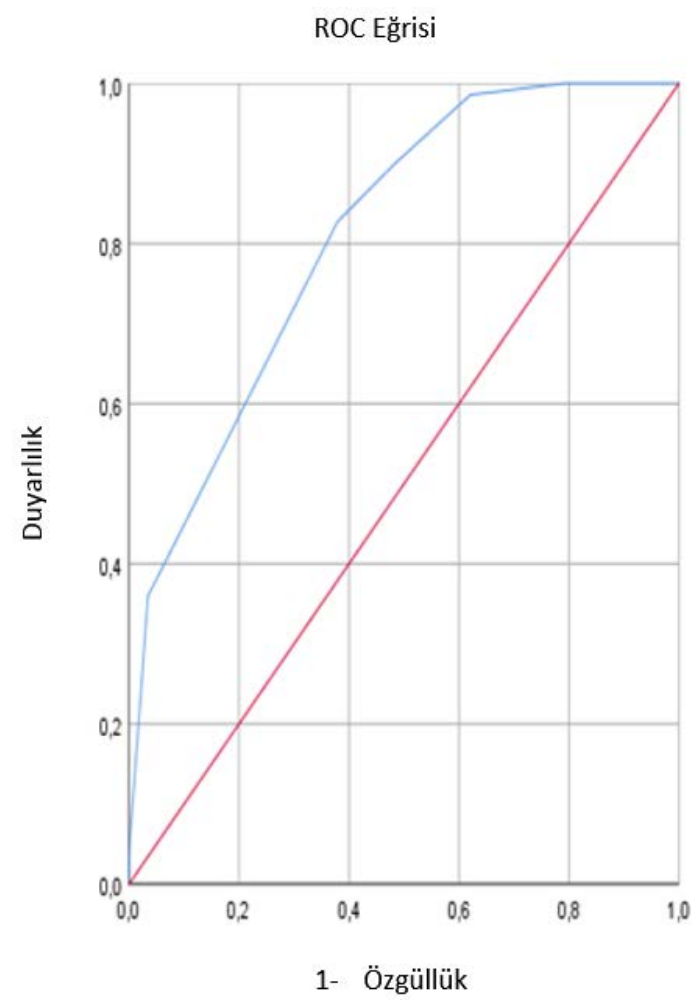

Şekil 2. Organik Gıda Ürünleri Satın Alma ROC Eğrisi.

Organik gıda ürünleri satın alma gücü (Evet ve Hayır ayırt edebilme gücü) Receiver Operating Characteristics (ROC) analizi eğrisinin altında kalan alan ile ifade edilir (Şekil 2). Alan değeri 1'e yaklaştıkça Organik Gıda Ürünleri Satın Alma gücü yükselir. Alan değeri 1'e eşit olunca Organik gıda ürünleri satın alma gücü \%100 olur.

Çizelge 3. Sınır değerleri için elde edilen duyarlılık, özgüllük ve (1 - özgüllük) değerleri

\begin{tabular}{lll}
\hline $\begin{array}{l}\text { Eğrinin Koordinatları } \\
\text { Kesim (tahmini referans) değeri }\end{array}$ & & \\
(pozitiflik alt sinırı) & Duyarlılık & 1 - Özgüllük \\
\hline$\geq-1.0000$ & 1.000 & 1.000 \\
$\geq .1429$ & 1.000 & .793 \\
$\geq .5179$ & .986 & .621 \\
$\geq .7596$ & .899 & .483 \\
$\geq .8179$ & .827 & .379 \\
$\geq .9225$ & .360 & .034 \\
\hline
\end{tabular}


Yukarıdaki çizelgeden görüldüğü gibi en uygun değerin 0.8179 olduğu görülmektedir (Çizelge 3). Yani eğer organik gıda ürünleri satın alma olasılık değeri 0.81792 'ye eşit ya da büyükse organik gıda ürünleri satın alma olasılığı arttığını söylemek mümkündür.

\section{Tartışma ve Sonuç}

Araştırmaya katılan tüketicilerin \%82.7'si organik gıda ürünleri satın alırken \%17.3'ü organik gıda ürünleri satın almadığını belirtmiştir. Benzer çalışmalara bakıldığında İnci ve ark. (2014) Bingöl İli kentsel alanda yaşayan bireylerin \%84.2'sinin, Sandallığlu (2014) Adana ili kentsel alanda yaşayan tüketicilerin \%68.5'inin, İnci ve ark. (2017) Diyarbakır ilindeki bireylerin \%54,5'inin, organik gida tükettiğini belirtmişlerdir. Katılımcıların çoğunun organik gıda tüketim sebeplerinin sağlık, ekonomi, hanede yaşayan birey sayısı ve bilinçli tüketim gibi parametrelerden kaynaklandığı düşünülebilir. Nitekim Zanoli ve Nıspetti (2002) sağlık, Schifferstein ve Ophius (1998) tat ve gıda güvenliği, Squires ve ark. (2001) çevre kaygısı, Hughner, (2007) hayvan refahı, yerel ekonomiyi destekleme arzusu, nostalji merak1 ve moda takibi gibi nedenlerin organik ürün tüketimi üzerinde etkisi olduğunu belirtmişlerdir. Yapılan bir çalışmada organik gıda tüketilmemesinin nedenleri olarak bilgi eksikliği ve organik gıdaların zor bulunması gösterilmiştir (Aydın, 2011).

Kadınların organik gıda tüketimi erkeklere oranla yüksek bulunmuştur. Aynı durum, İnci ve ark. (2017) tarafından da vurgulanmıştır. Benzer şekilde, kadınların alışverişe erkeklerden fazla çıkmaları ve sağlığına erkeklere oranla daha çok dikkat etmeleri organik tarıma ilgilerinin yüksek olduğunu gösterebilir. Thompson ve Kidwell, (1998), kadınların alışverişe erkeklere oranla daha fazla çıktıklarını, Hilverda ve ark. (2016) organik gidalara olan ilgi ve bilgi seviyeleri erkeklerden daha fazla olduğunu bildirmişlerdir. Çelik (2013) kadının gelirinin net ve evinde çocuklarının olması organik gıda satın alma olasılığının artmasına işaret etmekle beraber, Davis ve ark. (1995) ev geliri uygun olan çocuklu kadınların organik gıda satın alımında daimi birer müşteri olduğunu belirtmişlerdir.

Evli olanlar bekâr olanlardan daha fazla organik gıda satın almışlardır. Evli olanların daha fazla organik gıda tercih etmesi büyük ihtimalle ailede çocuğun bulunmasındandır. Hutchins ve Greenhalgh (1995), Midmore (2005) organik gıda satın alımında çocukların en önemli nedenler arasında olduğunu bildirmişlerdir.

Hanedeki birey sayısı organik gıda satın alımını etkileyen bir diğer faktördür. İki, üç ve dört çocuğu olanlar organik gıda satın alımında diğerlerine oranla fazlalıktadır. Eğer hanedeki bireyler arasında çocuk varsa ve ekonomileri uygunsa organik ürün tüketimi artmakta hane halkı kalabalık ve ekonomik durum kötü ise tam tersi olmaktadır. Hanedeki bireylerin fazlalığı hanede gelirin artmasına neden oluyorsa organik gıda tüketimi artmaktadır. Arpacı ve Ersoy (2003) hane halkı sayısı ekonomik ve benzer dağılımlarla etkileşimi olacağından refah seviyesini etkileyebileceğini, Kurt (2006) hanede ki birey sayısı fazlalığı ödeme isteğini düşürebileceğini, Uzundumlu ve Sezgin (2019) hanedeki dağılımın artmasının haneye gelen geliri de arttırması nedeniyle sağlıklı gıdalara fazla ödeme isteği oluşacağını, bildirmişlerdir.

Araştırmada okuryazar olmayan (doğal beslenmeye alıştığ için tercih edilmiş olabilir) ve lisansüstü eğitime sahip olanların organik gıda satın alımı \%100 bulunmuştur. Eğitim durumu ile organik ürün kullanımı arasında bir ilişki olduğu düşünülmektedir. Katılımcıların eğitim düzeyleri arttıkça ekonomik düzeylerinin de arttığı, bilgi ve gelir düzeyleri artanların organik gıda satın alımları da artmaktadır. Hassan ve ark. (2009) eğitim düzeyi yüksek kişilerce organik tarım ve gıda ürünlerinin daha fazla tercih edildiğini bildirmiş, ayrıca, demografik verilerin organik gıda satın alımında önemli faktörler olduğunu ifade etmiştir. Thompson (1998) eğitim, yaş, medeni durum, çocuk sayısı ve yaşları gibi demografik faktörlerin tüketicilerin organik gida talebini etkilediğini belirtmiştir.

Sonuç olarak organik gıda tüketiminde bilgi, hanedeki birey sayıs1, hane halkı gelir durumu, cinsiyet gibi faktörler önemli rol oynamaktadır. Eryılmaz ve ark. (2015), organik gida ürünlerinin maliyetleri düşürüldüğünde, bilhassa kitlesel iletişim araçlarından faydalanılarak organik gıda tüketiminin artırılması için yapılacak reklam ve tanıtım faaliyetlerinin katkı sağlayabileceğini belirtmiştir. 


\section{Kaynakça}

Anonim. (2020a). https://www.tarimorman.gov.tr/Konular/Bitkisel-Uretim/Organik-Tarim/GenelBilgiler Erişim Tarihi 21.09.2020.

Anonim. (2020b). https://www.nufusune.com/ Erişim Tarihi 21.09.2020.

Arpac1, F., \& Ersoy, A. F. (2003). Orta öğretimdeki gençlerin konut koşulları ve konutun gencin gelişimi üzerindeki etkilerinin incelenmesi. Gazi Üniversitesi Gazi Eğitim Fakültesi Dergisi, 23(3).

Aydın, G. (2011). Tüketicilerin gıda güvenliği bilinç düzeylerine etki eden faktörlerin analizi: samsun ili kentsel alan örneği. Fen Bilimleri Enstitüsü, Yüksek Lisans Tezi.

Chien, C. F., \& Chen, L. F. (2008). Data mining to improve personnel selection and enhance human capital: A case study in high-technology industry. Expert Systems with applications, 34(1), 280290.

Çalış, A., Kayapınar, S., \& Çetinyokuş, T. (2014). Veri madenciliğinde karar ağacı algoritmaları ile bilgisayar ve internet güvenliği üzerine bir uygulama. Journal Of Industrial Engineering (Turkish Chamber Of Mechanical Engineers), 25.

Çam, O., \& Karakaya, E. (2018). Siirt il merkezindeki tüketicilerin organik ürün tüketim tercihleri ve tercihlerini etkileyen faktörlerin belirlenmesi. Adnan Menderes Üniversitesi Zir. Fak. Der. 15, 33-41.

Çelik, S. (2013). Kimler, neden organik gıda satın alıyor? Bir alan araştırması. Selçuk Üniversitesi Sosyal Bilimler Enstitüsü Dergisi, (30), 93-108.

Davis, A., Titterington, A. J., \& Cochrane, C. (1995). Who buys organic food? A profile of the purchasers of organic food in N. Ireland. British Food Journal, 97(10), 17-23.

Eryılmaz, G. A., Demiryürek, K., \& Emir, M. (2015). Avrupa Birliği ve Türkiye'de organik tarım ve gıda ürünlerine karşı tüketici davranışları. Anadolu Tarım Bilimleri Dergisi, 30(2), 199-206.

FIBL, (2016). https://shop.fibl.org/chen/mwdownloads/download/link/id/747/ Erişim Tarihi 21.09.2020.

İnci, H., Karakaya, E., \& Şengül, A. Y. (2017). Organik ürün tüketimini etkileyen faktörler (Diyarbakır ili örneği). Tarim ve Doga Dergisi, 20(2), 137.

Hassan, D., Monier-Dilhan, S., Nichele, V., \& Simioni, M. (2009). Organic food consumption patterns in France (No. 1006-2016-79386).

Hilverda, F., Jurgens, M., \& Kuttschreuter, M. (2016). Word associations with "organic": what do consumers think of? British Food Journal.

Hughner, R. S., McDonagh, P., Prothero, A., Shultz, C. J., \& Stanton, J. (2007). Who are organic food consumers? A compilation and review of why people purchase organic food. Journal of Consumer Behaviour: An International Research Review, 6(2-3), 94-110.

İnci, H., Karakaya, E., Söğüt, B., \& Şengül, T. (2014). Organic Product Consumption And Customer Preferences İn Urban Sections Of Bingol Province. Türk Tarım Ve Doğa Bilimleri Dergisi, 1(2), 255-261.

Hakan, İ. N. C. İ., Karakaya, E., \& Şengül, A. Y. (2017). Organik ürün tüketimini etkileyen faktörler (Diyarbakır ili örneği). Tarim ve Doga Dergisi, 20(2), 137.

Karadas, K. \& Kadirhanogullari, I. H. 2017. Predicting Honey Production using Data Mining and Artificial Neural Network Algorithms in Apiculture. Pakistan Journal of zoology 49 (5), 16111619.

Karakaya, E., Çelik, Ş., \& Taysı, M. R. (2018). CHAID Algoritması ile Balık Eti Tüketimini Etkileyen Faktörlerin İncelenmesi. Gaziosmanpaşa Üniversitesi Ziraat Fakültesi Dergisi, 35(2), 85-93.

Kurga, C., \& Erdal, M. (2014). Ağrı İli Organik Tarım Ve Hayvancılık Mevcut Durum Analizi. https://orgprints.org/25776/ Erişim Tarihi 21.09.2020

Kurt, Z. (2006). Organik tarım ürünleri pazarlaması ve uygulamalar (Doctoral dissertation, DEÜ Sosyal Bilimleri Enstitüsü).

Midmore, P., Naspetti, S., Sherwood, A. M., Vairo, D., Wier, M., \& Zanoli, R. (2005). Consumer attitudes to quality and safety of organic and low input foods: a review. Report of EU-funded project "Improving Quality and Safety and Reduction of Cost in the European Organic and 'Low Input'Food Supply Chains.” Univ. Wales, Aberystwyth, UK.

Rehber, E., \& Turhan, S. (2002). Prospects and challenges for developing countries in trade and production of organic food and fibers. British Food Journal. 
Sandallığlu, A. (2014). Adana ilinde organik tarım ürünleri tüketimi ve tüketici eğilimleri. Çukurova Üniversitesi. Fen Bilimleri Enstitüsü, Tarım Ekonomisi Anabilim Dalı. Doktora Tezi. Adana.

Schifferstein, H. N., \& Ophuis, P. A. O. (1998). Health-related determinants of organic food consumption in the Netherlands. Food quality and Preference, 9(3), 119-133.

Squires, L., Juric, B., \& Cornwell, T. B. (2001). Level of market development and intensity of organic food consumption: cross-cultural study of Danish and New Zealand consumers. Journal of Consumer Marketing.

Thompson, G. D., \& Kidwell, J. (1998). Explaining the choice of organic produce: cosmetic defects, prices, and consumer preferences. American journal of agricultural economics, 80(2), 277-287.

Uzundumlu, A., \& Sezgin, A. (2019). Organik ürün tüketimi üzerine etkili olan faktörlerin analizi; Erzurum ili örneği. Ibad Sosyal Bilimler Dergisi, 441-451.

Yamane, T. (2010). Temel Örnekleme Yöntemleri. Literatür Yayınc1lık. ISBN;978-975-8431-34-2. İstanbul.

Zanol1, R., Nispett1, S. (2002). Consumer motivations in thepurchase of organicfood, British Food Journal, 104(8), 643-653. 